\title{
Spontaneous silent sinus syndrome (Imploding antrum syndrome): case series of 16 patients*
}

\author{
H. Babar-Craig ${ }^{1}$, H. Kayhanian ${ }^{1}$, D.J. De Silva², G.E. Rose², V.J. Lund ${ }^{1}$ \\ Royal National Throat Nose and Ear Hospital, London, WC1X 8DD, United Kingdom \\ Orbital Unit, Moorfields Eye Hospital, London EC1V 2PD, United Kingdom
}

SUMMARY Introduction: Silent sinus syndrome (SSS) is a rare idiopathic collapse of the maxillary sinus and orbital floor. We present the second largest series of sixteen patients with SSS and describe their management.

Methods: A cohort of 16 patients with spontaneous SSS between 1999 and 2009 were reviewed at the Royal National Throat Nose and Ear Hospital. All patients were initially referred from a postgraduate ophthalmic hospital, Moorfields Hospital.

Results: Fourteen patients required endoscopic sinus surgery to re-establish maxillary sinus drainage and the remaining two settled with intranasal medical therapy consisting of steroids and decongestions. Follow-up ranged from 6 months to 4 years with a mean of 2.6 years. An improvement in enophthalmos and was seen in all surgically treated patients with a mean improvement of $2.2 \mathrm{~mm}$ and range $0.5-4 \mathrm{~mm}$.

Discussion: SSS arises from congestion of the ostiomeatal complex resulting in negative pressure within the maxillary sinus and a gradual implosion of the antral cavity. Endoscopic sinus surgery successfully re-establishes maxillary aeration in our series and leads to clinical and aesthetic improvement in the degree of enophthalmos and has avoided the need for orbital floor repair in all but two cases.

Key words: spontaneous silent sinus syndrome, imploding antrum syndrome, maxillary sinus, enophthalmos

\section{INTRODUCTION}

Silent sinus syndrome (SSS) a unilateral collapse of the maxillary sinus and orbital floor associated with negative antral pressures in the absence of sinus symptoms was first described in 1994 by Soparkar and colleagues ${ }^{(1)}$ and is also known as the imploding antrum syndrome ${ }^{(2)}$. It typically presents with a 'sunken' eye (enophthalmos), a drop in the pupillary level (hypoglobus) and is characterised by a downward bowing of the orbital floor and a reduction in the size of the maxillary sinus.

Primary or spontaneous SSS is idiopathic occurring in adulthood and may become symptomatic over a period months to years, whereas secondary SSS may arise from mid-face trauma or chronic rhinosinusitis and has also been reported in less than $1 \%$ of patients after infero-medial orbital decompression for thyroid eye disease ${ }^{(3)}$. The primary condition is rare and to date only 105 cases would appear to have been reported in the English literature ${ }^{(4)}$ with the largest case series having 22 cases described by Kass et al. ${ }^{(5)}$ in 1997 and both Soparker et al. (1) in 1994 and Rose et al. ${ }^{(2)}$ in 2003 each report 14 cases of spontaneous SSS. We report the second largest case series of 16 patients with primary SSS and describe their clinical and radiological features and discuss the management of this condition.

\section{PATIENTS \& METHODS}

A cohort of patients with SSS treated between 1999 and 2009 were referred from a postgraduate ophthalmic hospital and managed at the Royal National Throat Nose and Ear Hospital. The diagnosis of primary SSS was based on the gradual onset of enophthalmos and/or hypoglobus, in the absence of orbital trauma (including surgery) or prior symptoms of sinus disease and with a typical smooth downward bowing of the orbital floor on imaging and evidence of opacification of the ipsilateral maxillary antrum.

\section{Surgical Management}

Fourteen patients were treated with endoscopic sinus surgery. Those with lateralised middle turbinates underwent trimming of the inferior portion of the turbinate combined with gentle medial displacement, to prevent re-occlusion of the natural 
maxillary ostium, which was enlarged to re-establish free ventilation of the maxillary sinus. Uncinectomy was performed with extra care as the inward implosion of the antral walls, in combination with a depressed orbital floor, placed the orbital contents at particular risk of injury. All cases were operated on by the senior author (VJL).

If clinically significant and symptomatic enophthalmos or hypoglobus persisted at 6 months after sinus surgery, the patient was considered for orbital floor repair with implantation of shaped silicone block through a lower eyelid swinging flap.

\section{RESULTS}

Sixteen patients (11 male, 69\%) presented with primary SSS between the ages of 14 and 79 years (mean 40.6, median 38 years). Symptoms had been present between 3 and 36 months (mean 14, median 12 months) and their signs included unilateral enophthalmos of 1 to $5 \mathrm{~mm}$ (mean 2.9, median $2.25 \mathrm{~mm}$ ) and up to $4 \mathrm{~mm}$ of hypoglobus. Interestingly $10(62 \%)$ patients had ipsilateral lateralisation of their middle turbinates which may have contributed to maxillary ostium obstruction and 9 $(56 \%)$ patients had a septal deviation to the affected side. Six patients $(38 \%)$ had a previous history of acute rhinosinusitis but none within six months of presentation. Imaging of all cases demonstrated a smooth depression of the orbital floor with contraction and opacification of the maxillary sinus.
Fourteen patients $(88 \%)$ underwent endoscopic sinus surgery to re-establish maxillary sinus drainage. The remaining 2 patients had minimal symptoms, one did not return for further treatment and the other has deferred treatment until symptoms become more clinically apparent.

Follow-up ranged from 6 months to 4 years (mean of 2.6, median 2.33 years). Patients were followed regularly after endoscopic sinus surgery with ophthalmologic assessment and an improvement in enopthalmus was seen in all surgically treated patients with a mean improvement of $2.2 \mathrm{~mm}$ (median $1.8 \mathrm{~mm}$, range $0.5-4 \mathrm{~mm}$. As a consequence it did not prove necessary to undertake a secondary procedure to insert an orbital prosthesis except in two cases (12\%).

\section{DISCUSSION}

Spontaneous SSS is rare characterised by unilateral enophthalmos and hypoglobus with radiological findings of ipsilateral smooth depression of the orbital floor and opacification of a collapsed maxillary sinus ${ }^{(2)}$.

The pathogenesis of this condition remains conjectural but prolonged congestion of the ostiomeatal complex probably results in persistent sub-atmospheric pressure in the maxillary sinus ${ }^{(2,3)}$ a finding compatible with $62 \%$ of our patients having a lateralised middle turbinates that obstructed the area of maxillary antral drainage. Kass reports maxillary antral pressures

Table 1. Clinical characteristics for 16 patients presenting with primary silent sinus syndrome (imploding antrum syndrome).

\begin{tabular}{|c|c|c|}
\hline Clinical characteristic & & Proportion affected \\
\hline Proportion of males & & $11 / 16(69 \%)$ \\
\hline Proportion of right sides & & $6 / 16(38 \%)$ \\
\hline Age at presentation & $\begin{array}{l}\text { Mean; median } \\
\text { Range }\end{array}$ & $\begin{array}{l}40.6 ; 38 \text { years } \\
14-79 \text { years }\end{array}$ \\
\hline Duration of symptoms & $\begin{array}{c}\text { Mean; median } \\
\text { Range }\end{array}$ & $\begin{array}{l}14.0 ; 12.0 \text { months } \\
3-36 \text { months }\end{array}$ \\
\hline Symptoms at presentation & $\begin{array}{c}\text { "Sunken eye" } \\
\text { Diplopia } \\
\text { Pain within ipsilateral maxilla } \\
\text { Nasal congestion } \\
\text { Remote history of acute sinusitis }\end{array}$ & $\begin{array}{l}7 / 16(44 \%) \\
5 / 16(32 \%) \\
7 / 16(44 \%) \\
10 / 16(62 \%) \\
6 / 16(38 \%)\end{array}$ \\
\hline Nasal and sinus imaging & $\begin{array}{l}\text { Contracted ipsilateral maxilla } \\
\text { Lateralised ipsilateral middle turbinate } \\
\text { Septum deviated to affected side }\end{array}$ & $\begin{array}{l}16 / 16(100 \%) \\
10 / 16(62 \%) \\
9 / 16(56 \%)\end{array}$ \\
\hline Preoperative enophthalmos ** & $\begin{array}{l}\text { Mean; median } \\
\text { Range }\end{array}$ & $\begin{array}{l}2.9 ; 2.25 \mathrm{~mm} \\
1-5 \mathrm{~mm}\end{array}$ \\
\hline Postoperative enophthalmos ** & $\begin{array}{l}\text { Mean; median } \\
\text { Range }\end{array}$ & $\begin{array}{l}0.7 ; 1.0 \mathrm{~mm} \\
1-2 \mathrm{~mm}\end{array}$ \\
\hline $\begin{array}{l}\text { Proportion undergoing } \\
\text { secondary repair of } \\
\text { orbital floor }\end{array}$ & & $2 / 16(12 \%)$ \\
\hline
\end{tabular}

** Enophthalmos taken as exophthalmometry relative to unaffected side. 


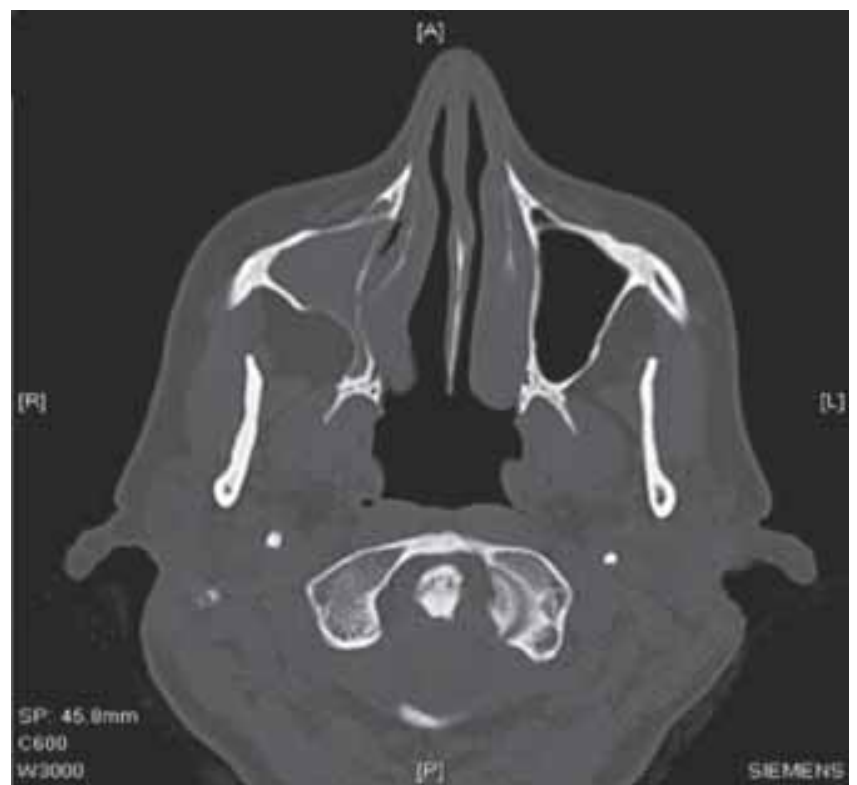

Figure 1. Patient presenting with primary silent sinus syndrome, axial CT showing maxillary opacity with inward bowing ("implosion") of the right maxillary walls that show patchy loss of mineralisation, and associated lateral displacement of the middle turbinate.

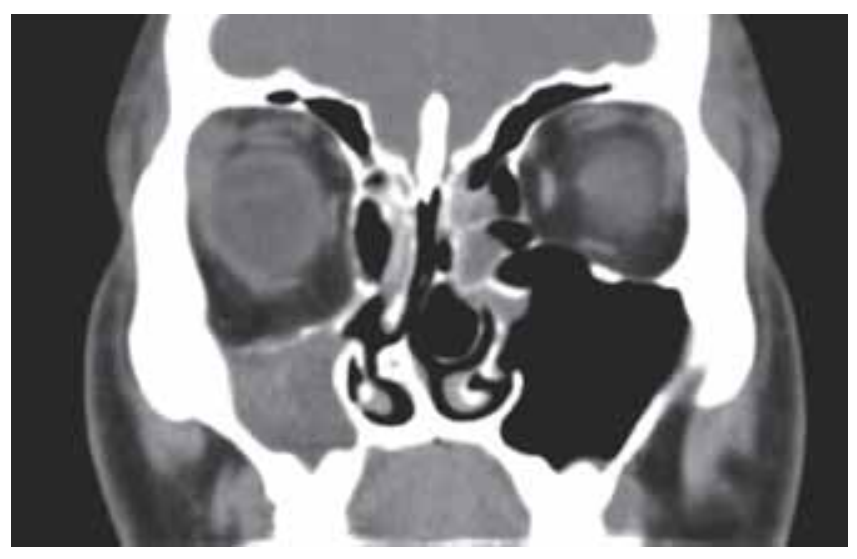

Figure 2. Coronal CT showing opacification of the right maxilla, smooth downward bowing of the demineralised orbital floor, and enophthalmos with hypoglobus.

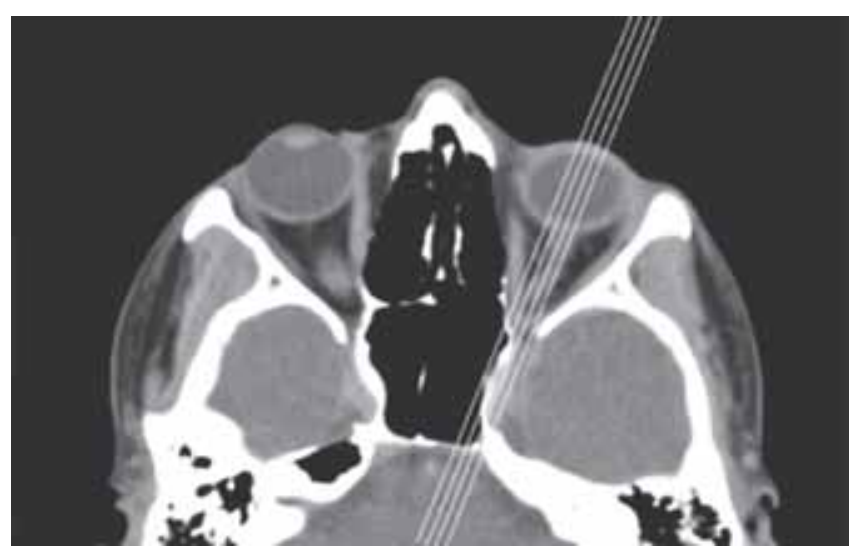

Figure 3. Enophthalmos in a patient with left SSS. of $-8.4 \mathrm{~cm} \mathrm{H}_{2} \mathrm{O}$ below atmospheric in manometric studies of patients with chronic maxillary atelectasis after obstruction of drainage ${ }^{(6)}$. The presence of chronic inflammation leads to loss of mineralisation of the antral bone and the low pressure causes shrinkage of the sinus cavity - an imploding antrum. An alternative hypothesis has suggested that the lateralised middle turbinate may act as a one-way pneumatic valve, leading to progressive reduction of air in the antrum and subsequent collapse of the maxillary sinus ${ }^{(7)}$.

Endoscopic sinus surgery is well-established for restoring sinus drainage, with minimal collateral damage, and has been shown to be of value in SSS ${ }^{(4,8,9)}$. We have shown that careful uncinectomy and middle meatal antrostomy provides successful maxillary aeration and, in many cases, leads to a marked improvement in orbital signs over 6 months after sinus surgery; indeed, only a small minority of our patients elected for secondary repair of the orbital floor for aesthetic reasons. The majority of patients will undergo remodelling of the maxillary sinus post-operatively such that secondary elevation of the orbital floor is unnecessary in the majority of patients and this two staged approach to orbital repair enabled avoidance of prosthetic insertion in all but two patients in our case series.

\section{REFERENCES}

1. Soparkar CN, Patrinely JR, Cuaycong MJ, et al. The silent sinus syndrome. A cause of spontaneous enophthalmus. Ophthalomology. 1994; 101: 772-778.

2. Rose GE, Sandy C, Hallberg L, Moseley I. Clinical and radiologic characteristics of the imploding antrum, or silent sinus syndrome. Ophthalmology. 2003; 110: 811-818.

3. Rose GE, Lund VJ. Clinical features and treatment of late enophthalmos after orbital decompression. A condition suggesting cause for idiopathic imploding antrum (silent sinus) syndrome. Ophthalmology. 2003; 110: 819-826.

4. Brandt MG, Wright ED. The silent sinus syndrome is a form of chronic maxillary atelectasis: A systematic review of all reported cases. Am J of Rhinol. 2008; 22: 68-73.

5. Kass ES, Salman S, Rubin PAD, et al. Chronic maxillary atelectasis. Ann Otol Rhinol Laryngol. 1997; 106: 109-116.

6. Kass E.S, Salman S, Montgomery W.W. Manometric study of complete ostial occlusion in chronic maxillary atelectasis. Laryngoscope. 1996; 106: 1255-1258.

7. Bossolesi P, Autelitano L, Brusati R, Castelnuovo P. The silent sinus syndrome: diagnosis and surgical treatment. Rhinology. 2008; 46: 308-316.

8. Blackwell KE, Goldberg RA, Calcaterra TC. Atelectasis of the maxillary sinus with enophthalmus and midface depression. Ann Otol Rhinol Laryngol. 1993; 102: 429-432.

9. Sciarretta V, Pasquini E, Tessi F, Modugno GC, Farneti G. Endoscopic sinus surgery for the treatment of maxillary sinus atelectasis and silent sinus syndrome. J Otolaryngol. 2006; 35: 60-64.

Miss Humera Babar-Craig

Royal National Throat Nose and Ear Hospital

London

\section{WC1X 8DD}

United Kingdom

E-mail: Humerababar1@aol.com 